
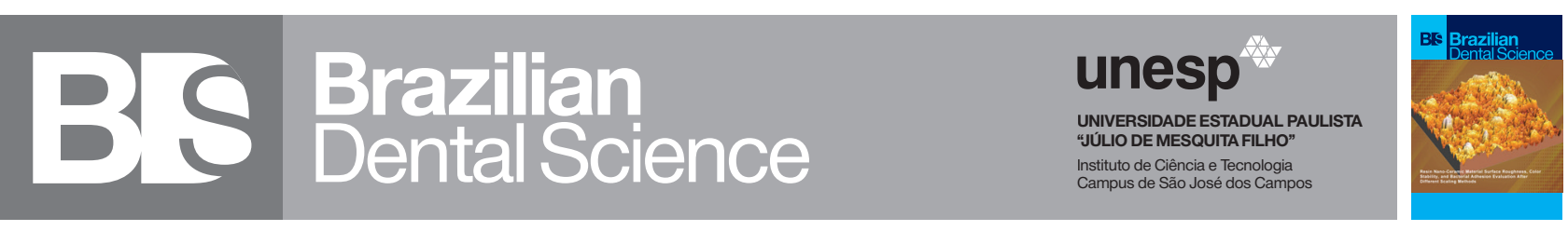

\title{
Polywave And Monowave Light-Curing Units Effects On Polymerization Efficiency Of Different Photoinitiators
}

\author{
Efeito Da Unidade De Cura Por Luz Polywave E Monowave Na Eficiência De Polimerização De Diferentes Fotoiniciadores
}

Peterson Oliveira BOEIRA ${ }^{1}$, Mateus de Azevedo KINALSKI ${ }^{1}$, Mateus Bertolini Fernandes dos SANTOS ${ }^{1}$, Rafael Ratto de MORAES ${ }^{1}$, Giana da Silveira LIMA ${ }^{1}$

1 - Graduate Program in Dentistry, Federal University of Pelotas, Pelotas, Brazil.

\section{ABSTRACT}

Objective: The objective of this study was to characterize and correlate the absorption spectra of three photoinitiators [camphorquinone (CQ), diphenyl(2,4,6-trimethylbenzoyl) phosphine oxide (TPO) and phenylbis (2,4,6-trimethylbenzoyl)phosphine oxide (BAPO)], using second or thirdgeneration light curing units (LCU), and to evaluate the degree of conversion and the physical properties of an experimental resin adhesive. Material and methods: Second-generation $\quad\left(\right.$ Radii-cal $^{\circledR}$ and Emitter $D^{\circledR}$ ) and third-generation (Valo ${ }^{\circledR}$ Cordless and Bluephase $\mathrm{N}^{\circledR}$ ) LCU were assessed regarding spectrum and irradiance rate of emitted light. Also, the photoinitiators (CQ, TPO and BAPO) were characterized by a light absorption spectrum assessed by UV-Vis spectroscopy, degree of conversion and yellowing effect. Statistical analyzes considered two-way ANOVA and post-hoc Tukey test. Results: BAPO presented higher reactivity compared to TPO. Regarding degree of conversion of the photoinitiators activated by different light-curing units, the Emitter $D^{\circledR}$ device promoted a high degree of conversion. BAPO presented the highest yellowing effect values. Conclusions: The emission and absorption characteristics of the photoinitiators were different. The polymerization reaction activated by the secondgeneration light-curing unit was reduced when using an experimental resin with photoinitiator TPO, and the third-generation light-curing unit showed a higher polymerization potential regardless of the photoinitiator.

\section{KEYWORDS}

Light-curing of dental adhesives; Photoinitiators dental; Curing lights dental.

\section{RESUMO}

Objetivo: Caracterizar e correlacionar os espectros de absorção de três fotoiniciadores [canforoquinona (CQ), difenil 2,4,6-trimetilbenzil óxido de fosfina (TPO) e óxido de di (2,4,6-trimetilbenzil) difenil fosfina (BAPO)], com unidades de fotoativação (LCU) de segunda ou terceira geração, e avaliar o grau de conversão e as propriedades físicas de um adesivo experimental. Material e métodos: LCU de segunda geração (Radii-cal ${ }^{\circledR}$ e Emitter $\mathrm{D}^{\circledR}$ ) e terceira geração (Valo ${ }^{\circledR}$ Cordless e Bluephase $\mathrm{N}^{\circledR}$ ) foram avaliadas quanto ao espectro e taxa de irradiância da luz emitida. Além disso, os fotoiniciadores (CQ, TPO e BAPO) foram caracterizados por um espectro de absorção de luz avaliado por espectroscopia UV-Vis, avaliado o grau de conversão dos adesivos e efeito de amarelamento. A análise estatística empregada foi ANOVA duas vias e teste post-hoc de Tukey. Resultados: BAPO apresentou maior reatividade comparado ao TPO. Em relação ao grau de conversão dos fotoiniciadores ativados por diferentes aparelhos fotopolimerizadores, o dispositivo Emitter $\mathrm{D}^{\circledR}$ promoveu um alto grau de conversão. BAPO apresentou os maiores valores de efeito de amarelamento. Conclusões: As características de emissão e absorção dos fotoiniciadores foram diferentes. A reação de polimerização ativada pelas unidades de fotopolimerização de segunda geração foi reduzida com o uso de uma resina experimental com fotoiniciador TPO. As unidades de fotopolimerização de terceira geração apresentaram maior potencial de polimerização independentemente do fotoiniciador.

\section{PALAVRAS-CHAVE}

Cura luminosa de adesivos dentários; Fotoiniciadores dentários; Luzes de cura dentária. 


\section{INTRODUCTION}

$\mathrm{T}^{\mathrm{h}}$ he evolution of conservative restorative dentistry has progressed significantly since the introduction of resin-based composites (RBC) and dental adhesives. Restorative procedures using these approaches have been widely used [1], offering tooth restoration that minimizes the wear of tooth structures [2]. In this respect, the adhesive systems used in these procedures are generally light-cured. For this reason, the photoinitiators contained in these systems must be present in adequate quantity to react properly with their respective light wavelength [3].

The most important characteristic of a dental adhesive is its bonding with the dental surface (enamel and/or dentin) [4]. The chemical composition of adhesive systems includes methacrylate monomers, solvents, and a system of photoinitiators [5]. One of the most common photoinitiators used in dental adhesives is camphorquinone (CQ) [6], although several other photoinitiators have been developed to reduce the impact of color instability, such as diphenyl(2,4,6trimethylbenzoyl) phosphine oxide (TPO) [8], and phenylbis (2,4,6-trimethylbenzoyl)-phosphine oxide (BAPO) [8]. These substances have been shown to have an adequate degree of $C=C$ conversion [9] of RBCs. In addition, it is uncertain what mechanical properties of these photoinitiators $[10,11]$ are satisfactory in relation to different light sources. To the best of our knowledge, these properties have not been evaluated in previously published studies. The greater results of dental adhesives must consider the light-curing process as critical toward achieving a satisfactory degree of conversion, to the extent that it will be able to improve the properties of these adhesive materials.

The light-curing process should be regarded as a critical step in the restorative procedure [12], and must involve an adequate light-curing unit (LCU). The first generation of LCUs was introduced in the late 90's. These LCUs produced a relatively low capacity of polymerization, mainly guaranteed by higher exposure time [13]. The second generation of LCUs saw some improvements, such as increased irradiance values and lower exposure time; however, these LCUs presented a reduced spectral emission wavelength, compared with that of the first generation (430$500 \mathrm{~nm}$ to $420-470 \mathrm{~nm}$ ) [14]. More recently, the third generation of LCUs was manufactured with a simultaneous combination of violet and blue wavelengths, which can provide a large spectrum of wavelengths, compared with the earlier models.

The yellowing effect is a physical parameter that can reliably demonstrate the optical behavior before and after material polymerization [15]. Considering it, the residual yellowing of composite resins can be considered an undesirable effect that occurs in dental restorations, impairing esthetics, and impacting the success of restorations [16]. Also, this yellowing can occur when the photoinitiator is not adequately polymerized [17].

Recent studies have demonstrated that some LCUs do not have a broad wavelength spectrum, needed to activate photoinitiators with different absorption peaks [18]. Since activation represents a critical step of the restorative procedure, it is important to understand the effects of these factors on this procedure.

Thus, this study aimed to characterize and correlate the absorption spectra of three photoinitiators (CQ, TPO and BAPO), using second-generation (Radii-cal ${ }^{\circledR}$ and Emitter $\mathrm{D}^{\circledR}$ ) and third-generation (Valo ${ }^{\circledR}$ Cordless and Bluephase $\mathrm{N}^{\circledR}$ ) LCU, evaluating the degree of conversion and the physical properties of an experimental resin adhesive. The hypothesis considered that the polymerization effect of second-generation (Radii$\mathrm{cal}^{\circledR}$ and Emitter $\mathrm{D}^{\circledR}$ ) and third-generation $\left(\right.$ Valo $^{\circledR}$ Cordless and Bluephase $\mathrm{N}^{\circledR}$ ) LCUs was similar considering degree of conversion. 


\section{MATERIALS AND METHODS}

\section{Reagents}

The following reagents were purchased to perform the research: bisphenol-A glycidyl dimethacrylate (Bis-GMA), triethylene glycol dimethacrylate (TEGDMA), 2-hydroxyethyl methacrylate (HEMA), and camphorquinone (CQ) (all directly from their manufacturer, Esstech, Essignton, USA), diphenyl(2,4,6trimethylbenzoyl)phosphine oxide (TPO), phenylbis (2,4,6-trimethylbenzoyl) phosphine oxide (BAPO), diphenyliodonium hexafluorophosphate (DPIHFP), ethyl 4-(dimethylamino)benzoate (EDAB) (all from Sigma-Aldrich Chemical, Milwaukee, USA), and toluene (Vetec, Rio de Janeiro, BRA).

\section{Study design}

Two $2^{\text {nd }}$ generation and two $3^{\text {rd }}$ generation LCUs were assessed for spectra and irradiance rate of emitted light. The photoinitiators were characterized by a light absorption spectrum. An experimental resin adhesive was prepared by mixing 50\% Bis-GMA, 25\% TEGDMA and 25\% HEMA. Additionally, three different initiator systems were included in the experimental adhesive, and evaluated in the following groups:

1) $\mathrm{CQ}(0.4 \%$ molar $)+\operatorname{EDAB}(0.8 \% \mathrm{~mol})$ + DPIHFP ( $1 \% \mathrm{~mol})$

2) BAPO (1\% mol) + DPIHFP (1\% mol)

3) TPO (1\% mol) + DPIHFP (1\% mol)

Physical properties, such as degree of conversion and yellowing effect, were tested using the different groups. This design enabled knowing the main outcomes of the response variables of each photoinitiator in relation to the LCUs.

\section{Light-emitting diode LCUs}

The LED (light-emitting diode) LCUs were chosen according to their generation, and to the difference in their light emission spectra. The second generation LCUs were Radii-cal ${ }^{\circledR}$ (SDI, Bayswater, AUS) and Emitter $\mathrm{D}^{\circledR}$ (Schuster, Santa Maria, BRA). The third generation LCUs were Valo ${ }^{\circledR}$ Cordless (Ultradent, South Jordan, USA) and Bluephase $\mathrm{N}^{\circledR}$ (Ivoclar Vivadent, Schaan, LI). The irradiance emitted was measured with the MARC $^{\circledR}$-Resin Calibrator (Bluelight Analytics, Halifax, Canada). The diameter of LCU tip was $6.8 \mathrm{~mm}$ (Radii-cal ${ }^{\circledR}$ and Emitter $\mathrm{D}^{\circledR}$, and Bluephase $\mathrm{N}^{\circledR}$ ) and $11.6 \mathrm{~m}$ (Valo ${ }^{\circledR}$ Cordless). Each LCU was tested in a standard position, $0 \mathrm{~mm}$ from the sensor, with 20 -second light activation. The mean irradiance $\left(\mathrm{mW} / \mathrm{cm}^{2}\right)$, total energy density $\left(\mathrm{J} / \mathrm{cm}^{2}\right)$, energy distribution per spectrum $\left(\mathrm{J} / \mathrm{cm}^{2}\right)$, and spectral irradiance $\left(\mathrm{mW} / \mathrm{cm}^{2} / \mathrm{nm}\right)$ of each LED light were considered.

\section{UV-VIS Spectroscopy}

The UV-VIS was recorded using a UV/ VIS Hitachi UV-2450 spectrometer (Shimadzu, Columbia, USA). The spectrophotometric analysis was performed to evaluate the photoinitiator light absorption in the spectral range of 200-600 nm. All photoinitiators were diluted in a $1.0 \times 10^{-3}$ toluene solution. These specters were collected using a 1-cm-long quartz cell.

\section{Degree of conversion}

The degree of $\mathrm{C}=\mathrm{C}$ conversion of the experimental resin adhesive was evaluated by Fourier transformed infrared spectroscopy using a Prestige 21 spectrometer (Shimadzu, Tokyo, JAP), equipped with an attenuated reflectance device composed of a horizontal ZnSe crystal with a $45^{\circ}$ mirror angle (PIKE Technologies, Madison, USA). The IRSolution software package (Shimadzu, Columbia, USA) was used in the monitoring scan mode using Happ-Genzel apodization in the $1500-1800 \mathrm{~cm}^{-1}$ range, with $4 \mathrm{~cm}^{-1}$ resolution and $2.8 \mathrm{~mm} / \mathrm{s}$ mirror speed. The analysis was performed at a controlled temperature of $23^{\circ}$ Celsius $\left( \pm 2^{\circ} \mathrm{C}\right)$ and relative humidity of $60 \%( \pm 5 \%)$. The sample $(3 \mu \mathrm{L})$ 
was distributed directly in the crystal diamond, and light activated for 20 seconds. The degree of conversion was calculated based on the intensity of the carbon-carbon double bond stretching vibrations (peak height) at $1635 \mathrm{~cm}^{-1}$, using a symmetric ring stretching at $1610 \mathrm{~m}^{-1}$ from the polymerized and non-polymerized samples as an internal standard. The analyses were performed in triplicate [19].

\section{Yellowing effect}

Cylindrical samples $(n=6)$ were obtained by inserting experimental resin adhesive into silicon models (6 mm diameter x $1 \mathrm{~mm}$ thick). The top and bottom surfaces of the specimens were light-activated using the LCU Valo $^{\circledR}$ Cordless. Analysis of the yellowing effect was performed with a portable spectrophotometer (X-Rite SP60, Grand Rapids, USA) to measure the $b$ * axis of the CIELAB system. This parameter measures the yellow color of a material, where higher values of the $\mathrm{b}$ * axis represent a higher yellowing effect [17].

\section{Statistical analysis}

Statistical analyzes were performed using the SigmaStat software package. The results of the degree of conversion were submitted to statistical two-way ANOVA. The results of the yellowing effect were evaluated statistically by one-way ANOVA and the post-hoc Tukey test.

\section{RESULTS}

Figure 1 shows the results of the absorption spectra of different photoinitiators. BAPO presented higher reactivity, compared with TPO. Note that both photoinitiators were limited to the proximal wavelength $(440 \mathrm{~nm}$ and $420 \mathrm{~nm}$ respectively). However, CQ+EDAB showed lower reactivity with the same 1.0x10-3 toluene concentration, but a broader absorption spectrum (400nm-500nm, with maximum length of $468 \mathrm{~nm}$ ) than groups BAPO and TPO.

Figure 2 compares the light emission spectra between $2^{\text {nd }}$ generation and $3 \mathrm{rd}$ generation LCUs. The $3^{\text {rd }}$ generation LCU presented a broad light spectrum and higher values compared than the $2^{\text {nd }}$ generation. However, Valo ${ }^{\circledR}$ Cordless (peak at 400-468nm) presented higher values than Bluephase $\mathrm{N}^{\circledR}$ (A) (peak at $410-458 \mathrm{~nm}$ ) considering the $3^{\text {rd }}$ generation, while in 2nd generation presented similar values [LCU Radii-cal ${ }^{\circledR}$ (D) (peak at 420500nm) and Emitter $D^{\circledR}$ (peak at 420-500nm)]

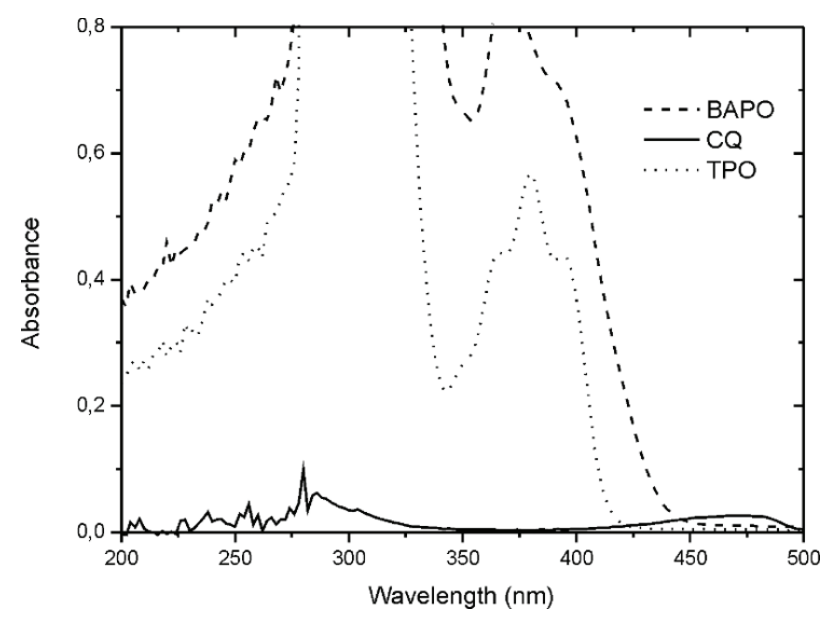

Figure 1 - Absorption spectrum (nm) by UV-VIS of different photoinitiators: BAPO, TPO and $\mathrm{CQ}$, all dilution in a toluene solution of $1.0 \times 10^{-3}$.

Figure 2 presents the correlation between the absorption spectra of the photoinitiators and the absolute irradiance spectra for the different LCUs. The Bluephase $\mathrm{N}^{\circledR}$ (A) and Valo ${ }^{\circledR}$ Cordless (B) showed two different peaks that reacted to the absorption spectra of all the photoinitiators. The Radii-cal ${ }^{\circledR}$ (D) and Emitter $D^{\circledR}$ (C) LCUs showed a light emission peak associated only with the CQ photoinitiator. 
A

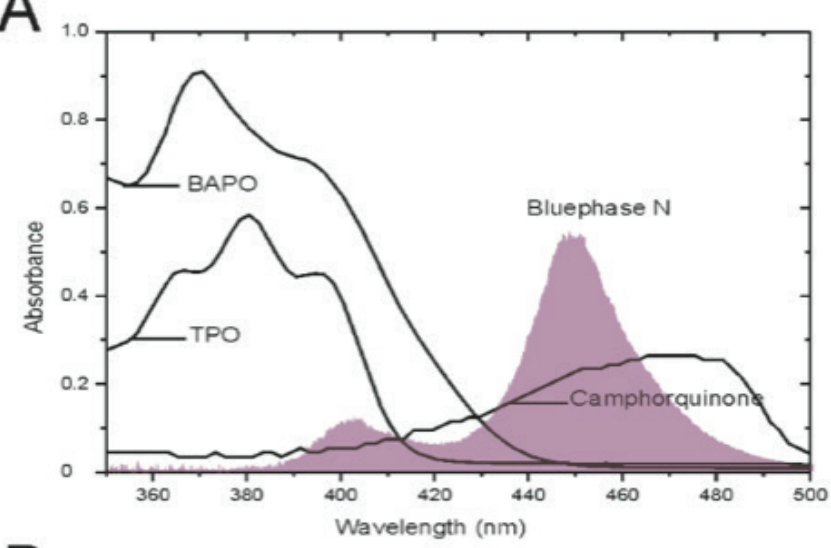

B

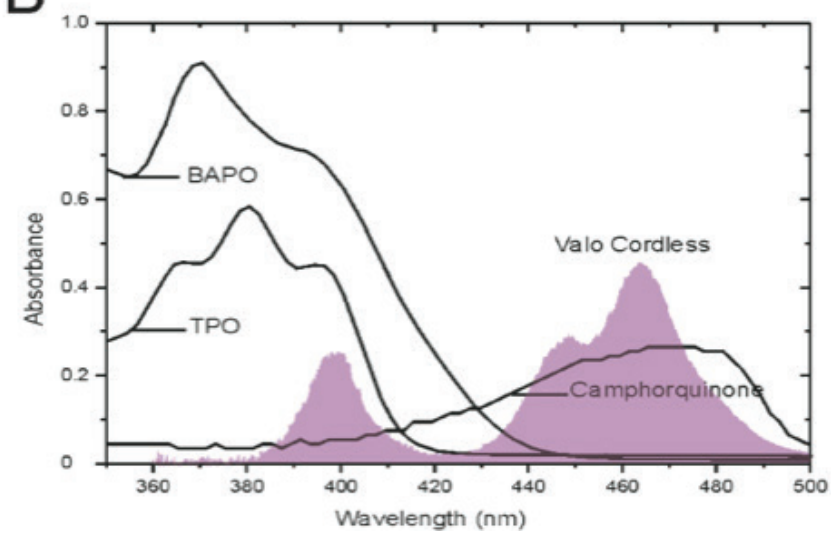

C

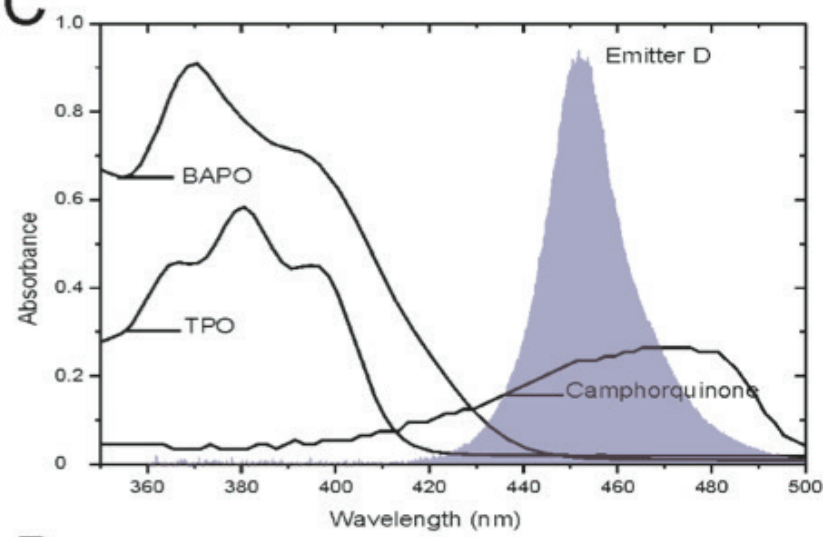

D

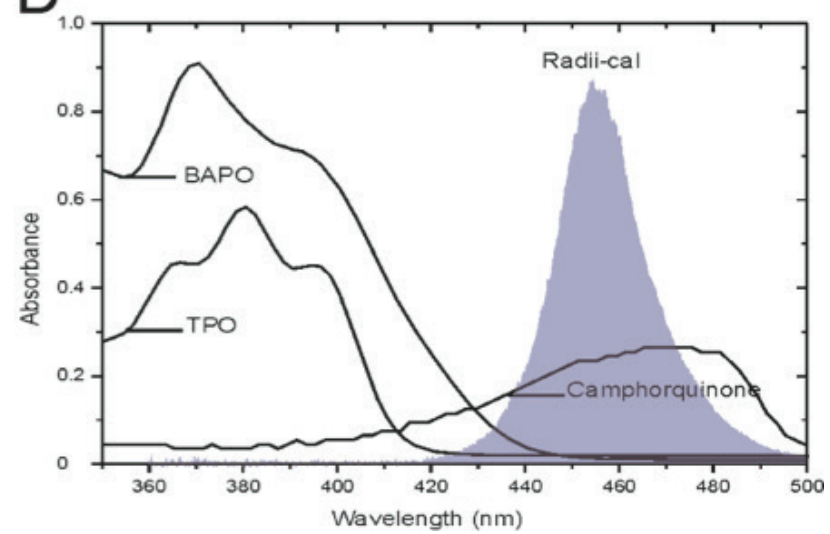

Figure 2 - Light emission spectrum from $2^{\text {nd }}$ generation or $3^{\text {rd }}$ generation LCUs manufactured by Bluephase $N^{\circledR}(A)$, Valo ${ }^{\circledR}$ Cordless $(B)$, Emitter $D^{\circledR}(C)$ and Radii-cal ${ }^{\circledR}(D)$, with correlation between absorption spectrum of photoinitiators and absolute irradiance of different LCUs.

Table I presents the values of diameter of LCUs tips, light wavelength characteristics, and mean/ standard deviation of irradiance evaluated in each light curing unit.

Table I - Values of diameter of LCUs tips, light wavelength characteristics, and mean/ standard deviation of irradiance evaluated in each light curing unit

\begin{tabular}{|c|c|c|c|}
\hline $\begin{array}{l}\text { Light Curing } \\
\text { Units }\end{array}$ & $\begin{array}{l}\text { Diameter of tip } \\
\text { (mm) }\end{array}$ & $\begin{array}{l}\text { Wavelenght } \\
\text { (nm) }\end{array}$ & $\begin{array}{c}\text { Irradiance Mw/ } \\
\text { cm }^{2}\end{array}$ \\
\hline \multicolumn{4}{|l|}{ Third-generation } \\
\hline Valo ${ }^{\circledast}$ Cordless & 11.6 & $380-500$ & $1304.54(2.1)$ \\
\hline Bluephase $\mathrm{N}^{\circledast}$ & 6.8 & $380-497$ & $1176.33(4.5)$ \\
\hline \multicolumn{4}{|c|}{ Second-generation } \\
\hline Radii-cal $^{\circledR}$ & 6.8 & $420-498$ & 1548.667 (12.7) \\
\hline Emitter D ${ }^{\circledR}$ & 6.8 & $318-49$ & $1518.333(12.5)$ \\
\hline
\end{tabular}

Table II shows the degree of conversion of photoinitiators activated by different LCUs. Regarding camphorquinone, the Emitter $\mathrm{D}^{\circledR}$ presented a statistically significant difference $(\mathrm{p}$ $<0.05$ ) considering the degree of conversion of an experimental resin adhesive. Considering BAPO, the values were similar and did not present statistically significant differences ( $p>$ 0.05). However, the degree of conversion of TPO presented the lower values when $2^{\text {nd }}$ generation LCUs were tested, while presented the higher values when $3^{\text {rd }}$ generation LCUs. 
Table II - Values of diameter of LCUs tips, light wavelength characteristics, and mean/ standard deviation of irradiance evaluated in each light curing unit

\begin{tabular}{|c|c|c|c|}
\hline \multirow[b]{2}{*}{$\begin{array}{l}\text { Light Curing } \\
\text { Units }\end{array}$} & \multicolumn{3}{|c|}{ Photoinitiators } \\
\hline & Camphoroquinone & BAPO & TPO \\
\hline \multicolumn{4}{|l|}{ Third-generation } \\
\hline Valo ${ }^{\circledR}$ Cordless & $67.0(0.5)^{\mathrm{Bb}}$ & $74.2(3.6)^{\text {Aa }}$ & $77.8(3.0)^{\text {Аа }}$ \\
\hline Bluephase ${ }^{\circledR}$ & $72.1(3.8)^{\mathrm{Ba}}$ & $74.8(3.8)^{\mathrm{Aa}}$ & $76.3(3.8)^{\text {Аа }}$ \\
\hline \multicolumn{4}{|c|}{ Second-generation } \\
\hline Radii-cal $^{\circledR}$ & $74.0(0.7)^{\mathrm{Ba}}$ & $72.4(7.9)^{\mathrm{Aa}}$ & $0.2(0.1)^{\mathrm{cb}}$ \\
\hline Emitter $D^{\circledR}$ & $77.8(2.3)^{\mathrm{Aa}}$ & $77.0(5.2)^{\mathrm{Aa}}$ & $41.0(3.2)^{\mathrm{Bb}}$ \\
\hline
\end{tabular}

Figure 3 shows the yellowing effect of different photoinitiators. A statistically significant difference was found among the groups: BAPO presented the highest yellowing effect values (11.25 \pm 0.56$)$, followed by CQ $(9.00 \pm 0.38)$, and TPO $(4.46 \pm 0.34)$ had the lowest values $(\mathrm{p}<0.05)$.

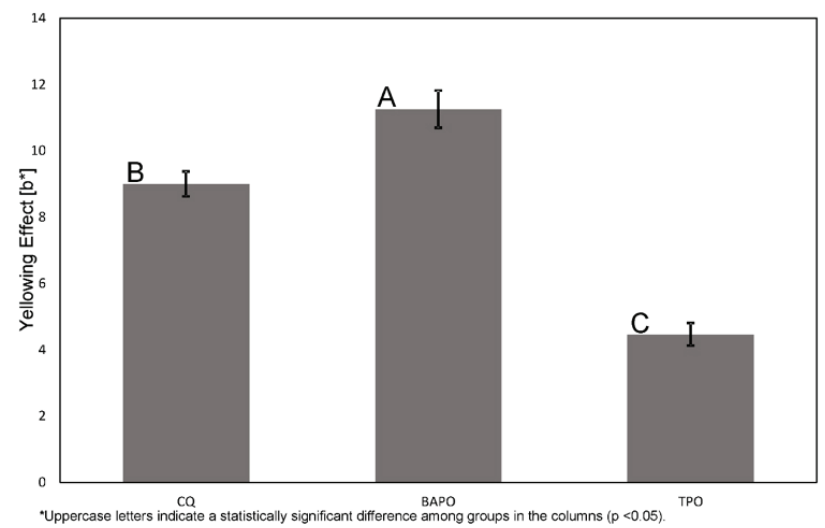

Figure 3 - Mean and standard deviation from yellowing-effect $\left[b^{*}\right]$ of an experimental resin adhesive containing different photoinitiators.

\section{DISCUSSION}

To the best of our knowledge, this is one of few studies to evaluate the effects of four different LCUs (two $2^{\text {nd }}$ and two $3^{\text {rd }}$ generation units) regarding the degree of conversion of three photoinitiators (BAPO, TPO, and CQ). Whilst the polymerization effect was different among the LCUs $\left[2^{\text {nd }}\right.$ generation Radii-cal ${ }^{\circledR}$, Emitter $\mathrm{D}^{\circledR}$; $3^{\text {rd }}$ generation Valo ${ }^{\circledR}$ Cordless), the Bluephase $\mathrm{N}^{\circledR}$ (3rd generation) presented similar degree of conversion considering all photoinitiators. One of the main results demonstrated the $2^{\text {nd }}$ generation LCU Radii-cal ${ }^{\circledR}$ did not present efficiency in relation to the degree of conversion considering TPO, whereas Emitter $\mathrm{D}^{\circledR}$ presented a decrease degree of conversion if compared to $3^{\text {rd }}$ generation LCUs. Thus, the study hypothesis was partially rejected.

Considering the properties of light emission, $3^{\text {rd }}$ generation LCUs are capable of emitting a broad wavelength spectrum due to the polywave characteristic and more similarities to the spectrum of UV-Lights. A recent study comparing $2^{\text {nd }}$ and $3^{\text {rd }}$ generation LCUs, the more recently launched Bluephase G2 and Valo ${ }^{\circledR}$ Cordless LCUs presented emission peaks of $410-460 \mathrm{~nm}$ and $410-455 \mathrm{~nm}$, respectively, whereas the 2nd generation Bluephase G1 had a peak of about $460 \mathrm{~nm}$ [20]. In this respect, RBCs that present a photoinitiator with an absorption spectrum between $420 \mathrm{~nm}$ and 460 $\mathrm{nm}$, like TPO, cannot properly initiate a degree of conversion, corroborating the results of the present study, in which TPO did not convert properly when a 2nd generation LCU was used. However, considering camphorquinone, the Emitter $\mathrm{D}^{\circledR}$ presented a statistically significant difference $(\mathrm{p}<0.05)$, with higher values of degree of conversion compared to $3^{\text {rd }}$ generation. It could be explained by the higher irradiance and spectrum of light emission specifically act in the absorption peak of this photoinitiator.

In this perspective, the light absorption peak values of each photoinitiators are important once it demonstrate the ability of LCU in promote an adequate degree of conversion. This characteristic is clinically important, because a not adequate degree of conversion could impact in the final restoration. In our study, BAPO and TPO, novel photoinitiators, demonstrated a narrow wavelength absorption spectrum (peaks between $440 \mathrm{~nm}$ and $420 \mathrm{~nm}$ respectively) if 
compared to CQ (maximum peak at $468 \mathrm{~nm}$ ) when $2^{\text {nd }}$ generation LCUs were tested. In this perspective, some studies have reported the incompatibility of some photoinitiators due to the differences the absorption spectrum range [20]. Bear in mind that the absorption spectrum of the TPO was in the range of $360 \mathrm{~nm}$ to 425 $\mathrm{nm}$, whereas that of the CQ lay in a broader spectrum of absorption, from $400 \mathrm{~nm}$ to 500 $\mathrm{nm}$ it could suggest that a probable reduction in the polymerization-related properties could be founded. It occurs due to differences between the emission spectra of 2 generation LCUs and the absorption spectra of these photoinitiators. The use of diphenyliodonium hexafluorophosphate during the excitation of CQ decomposes into salt in phenyliodonium and free phenyl radicals and this process facilitates the initiation of the polymerization reaction between monomers thus generating more reactive and increasing the reactivity of methacrylate polymerization. Therefore, diphenyliodonium hexafluorophosphate was as a catalyst for the polymerization reaction $[21,22]$. Finally, it is noteworthy to mention once this procedure is bilateral, demonstrating that the LCU must be chosen in agreement with resin composites which presents a photoinitiator that can be activated by a specifically light emission spectrum.

As seen in the present study, the relationship between the LCU and the light emission spectrum may impact the result of the dental restoration, since there are different RBCs use different photoinitiators. In clinical practice, if the dentist is not aware of the specific wavelength required by an RBC composition, the final dental restoration may not reproduce the most adequate characteristics in the oral environment. Also, as expected, the yellowing effect of BAPO and CQ was higher than that of TPO. It is widely recognized that the greater the CQ concentration, the greater the yellowing effect, since the chemical structure of CQ has some substances that will be responsible for a shift in the color stability according to the light absorption [23]. However, some studies have compared the color stability of these photoinitiators when used together, and the combination resulted in higher color stability with a lower degree of yellowing [24]. In addition, some RBCs manufactured with TPO have presented greater staining stability and less yellowing effect, compared with composites containing BAPO and CQ [25].

\section{CONCLUSION}

The main outcomes found in this study were:

- The emission and absorption characteristics were different depending on the LCUs and the photoinitiators.

- The polymerization reaction activated by the 2nd generation LCU was reduced when using an experimental resin adhesive with TPO.

- One LCU of third-generation presented a similar degree of conversion for all photoinitiators.

\section{Acknowledgments}

This study was funded in part by the Coordination for the Improvement of Higher Education Personnel (CAPES), Funding Code 001. The Brazilian National Research Council (CNPq) and the National Council for Scientific and Technological Development (CAPES) supported the authors (grants \#141524/20189 - POB, and \#8882.346916/2019-01 - MAK). The authors declare no conflict of interest.

\section{Funding}

- This study was partially supported by Conselho Nacional de Desenvolvimento Científico e Tecnológico - CNPq (grants \#141524/2018-9).

- This study was financed in part by the Coordenação de Aperfeiçoamento de Pessoal de 
Nível Superior - Brasil (CAPES) - Finance Code 001.

\section{Conflict of interest}

The authors have no proprietary, financial, or other personal interest of any nature or kind in any product, service, and/or company that is presented in this article.

\section{Regulatory Statement}

Not applicable.

\section{REFERENCES}

1. Ferracane JL. Resin composite--state of the art. Dent Mater. 2011 Jan;27(1):29-38. doi: 10.1016/.jdental.2010.10.020. Epub 2010 Nov 18. PMID: 21093034.

2. Mackenzie L, Banerjee A. Minimally invasive direct restorations: a practical guide. Br Dent J. 2017 Aug 11;223(3):163-71. doi:10.1038/sj.bdj.2017.661.PMID: 28798466.

3. Ferracane JL, Hilton TJ, Stansbury JW, Watts DC, Silikas N, llie N, et al. Academy of Dental Materials guidance-Resin composites: Part II-Technique sensitivity (handling, polymerization, dimensional changes). Dent Mater. 2017 Nov;33(11):1171-91. doi:10.1016/j.dental.2017.08.188. Epub 2017 Sep 13. PMID: 28917571

4. Van Meerbeek B, Yoshihara K, Yoshida Y, Mine A, De Munck J, Van Landuyt KL. State of the art of self-etch adhesives. Dent Mater. 2011 Jan;27(1):17-28. doi:10.1016/j.dental.2010.10.023. Epub 2010 Nov 24. PMID:21109301.

5. Rosa WL, Piva E, Silva AF. Bond strength of universal adhesives: a systematic review and meta-analysis. J Dent. 2015 Jul;43(7):765-76. doi:10.1016/j. jdent.2015.04.003. Epub 2015 Apr 14. PMID:25882585.

6. Santini A, Gallegos IT, Felix CM. Photoinitiators in dentistry: a review. Prim Dent J. 2013 0ct;2(4):30-3. doi:10.1308/205016814809859563. PMID: 24466621 .

7. Albuquerque PP, Moreira AD, Moraes RR, Cavalcante LM, Schneider LF.Color stability, conversion, water sorption and solubility of dental composites formulated with different photoinitiator systems. JDent. 2013 Aug;41 Suppl 3:e67-72. doi: 10.1016/j.jdent.2012.11.020. Epub 2012 Dec 8. PMID: 23228497.

8. Salgado VE, Borba MM, Cavalcante LM, Moraes RR, Schneider LF. Effect of photoinitiator combinations on hardness, depth of cure, and color of model resin composites. J Esthet Restor Dent. 2015 Mar-Apr;27 Suppl 1:S41-8. doi: 10.1111/jerd.12146. PMID: 25913451.

9. Meereis CT, Leal FB, Lima GS, de Carvalho RV, Piva E, Ogliari FA. BAPO as an alternative photoinitiator for the radical polymerization of dental resins. Dent Mater.2014 Sep;30(9):945-53. doi:10.1016/j.dental.2014.05.020. Epub 2014 Jun 21. PMID: 24962989.

10. Besse V, Derbanne MA, Pham TN, Cook WD, Le Pluart L. Photopolymerization study and adhesive properties of self-etch adhesives containing bis(acyl)phosphine oxide initiator. Dent Mater. 2016 Apr;32(4):5619. doi: 10.1016/j.dental.2016.01.005. Epub 2016 Feb 11. PMID: 26874789.
11. Borges BCD, Sousa-Lima RXd, Moreno GBP, Moreira DGL, Oliveira DCRS, Souza-Junior EJC, et al. Polymerization and adhesion behavior of experimental dental bonding materials with different initiator systems. J Adhes Sci Technol. 2018;32(3):239-46.

12. Munchow EA, Meereis CTW, de Oliveira da Rosa WL, da Silva AF, Piva E. Polymerization shrinkage stress of resin-based dental materials: A systematic review and meta-analyses of technique protocol and photoactivation strategies. J Mech Behav Biomed Mater. 2018;82:77-86.

13. Price RBT. Light curing in dentistry. Dent Clin North Am. 2017 0ct;61(4):75178. doi:10.1016/j.cden.2017.06.008.PMID:28886767.

14. Rueggeberg FA, Giannini M, Arrais CAG, Price RBT. Light curing in dentistry and clinical implications: a literature review. Braz Oral Res. 2017 Aug 28;31(suppl 1):e61. doi: 101590/1807-3107BOR-2017.vol31.0061.PMID: 28902241.

15. Brackett MG, Brackett WW, Browning WD, Rueggeberg FA. The effect of light curing source on the residual yellowing of resin composites. Oper Dent. 2007 Sep-0ct;32(5):443-50. doi:10.2341/06-129. PMID:17910220.

16. Prieto LT,Pimenta de Araújo CT, Araujo Pierote JJ, Salles de Oliveira DCR, Coppini EK, Sartini Paulillo LAM. Evaluation of degree of conversion and the effect of thermal aging on the color stability of resin cements and flowable composite. J Conserv Dent. 2018 Jan-Feb;21(1):47-51. doi: 10.4103/JCD. JCD 128 17.PMID:29628647;PMCID:PMC5852935.

17. Schneider LF, Pfeifer CS, Consani S, Prahl SA, Ferracane JL. Influence of photoinitiator type on the rate of polymerization, degree of conversion, hardness and yellowing of dental resin composites. Dent Mater. 2008 Sep;24(9):1169-77. doi: 10.1016/j.dental.2008.01.007.Epub 2008 Mar 5. PMID: 18325583.

18. Porto IC, Soares LE, Martin AA, Cavalli V, Liporoni PC. Influence of the photoinitiator system and light photoactivation units on the degree of conversion of dental composites. Braz Oral Res. 2010 0ct-Dec;24(4):475-81. doi:10.1590/s1806-83242010000400017.PMID:21180971.

19. Herrera-González AM, Caldera-Villalobos M, Pérez-Mondragón AA, CuevasSuárez CE, González-López JA. Analysis of Double Bond Conversion of Photopolymerizable Monomers by FTIR-ATR Spectroscopy. J Chem Educ. 2019;96(8):1786-9.

20. Santini A, Miletic V, Swift MD, Bradley M. Degree of conversion and microhardness of TPO-containing resin-based composites cured by polywave and monowave LED units. J Dent. 2012 Jul;:40(7):577-84. doi: 10.1016/j.jdent.2012.03.007. Epub 2012 Mar 29. PMID:22465876.

21. Dressano D, Palialol AR, Xavier TA, Braga RR, Oxman JD, Watts DC, et al. Effect of diphenyliodonium hexafluorophosphate on the physical and chemical properties of ethanolic solvated resins containing camphorquinone and 1-phenyl-1,2-propanedione sensitizers as initiators. Dent Mater. 2016 Jun;32(6):756-64. doi: 10.1016/j.dental.2016.03.010. Epub 2016 Apr 3.PMID:27048975.

22. Ogliari FA, Ely C, Petzhold CL, Demarco FF, Piva E. Onium salt improves the polymerization kinetics in an experimental dental adhesive resin. J Dent. 2007 Jul;35(7):583-7. doi: 10.1016/j.jdent.2007.04.001. Epub 2007 May 30. PMID: 17540492.

23. Maciel DDSA, Caires-Filho AB, Fernandez-Garcia M, Anauate-Netto C, Alonso RCB. Effect of camphorquinone concentration in physicalmechanical properties of experimental flowable resin composites. Biomed Res Int. 2018 May 22;2018:7921247.doi: 10.1155/2018/7921247.PMID: 29951545; PMCID:PMC5987321. 
Polywave And Monowave Light-Curing Units Effects On Polymerization Efficiency Of Different Photoinitiators

24. Salgado VE, Borba MM, Cavalcante LM, Moraes RR, Schneider LF.Effect of photoinitiator combinations on hardness, depth of cure, and color of model resin composites. J Esthet Restor Dent. 2015 Mar-Apr;27 Suppl 1:S41-8. doi: 10.1111/jerd.12146. PMID: 25913451.
25. Sampaio CS, Atria PJ, Rueggeberg FA, Yamaguchi S, Giannini M, Coelho PG, et al. Effect of blue and violet light on polymerization shrinkage vectors of a CQ/TPO-containing composite. Dent Mater. 2017 Jul;33(7):796-804. doi: 10.1016/j.dental.2017.04.010. Epub 2017 May 15.PMID: 28522161.

Profa. Dra. Giana da Silveira Lima

(Corresponding address)

Programa de Pós-graduação em Odontologia. Universidade Federal de Pelotas - UFPel.

Faculdade de Odontologia - Sala 504. Gonçalves Chaves, 457. Centro. Pelotas-RS.

Email: gianalima@gmail.com 